\title{
Taming the shrew: regulating prisoners through women-centered mental health programming
}

\author{
Kathy Kendall $\cdot$ Soshana Pollack
}

Published online: 20 June 2007

(C) Springer Science+Business Media B.V. 2007

\section{Erratum to: Crit Crim \\ DOI 10.1007/s10612-004-6168-5}

Please note that the author information on the title page of this article is incorrect.

The correct author information in alphabetical order should be:

Kathy Kendall

School of Medicine, University of Southampton

and

Soshana Pollack

Wilfried Laurier University

The online version of the original article can be found under doi: 10.1007/s10612-004-6168-5

K. Kendall ( $₫)$

School of Medicine, University of Southampton, Southampton, UK

e-mail: K.A.Kendall@ soton.ac.uk

S. Pollack

Wilfried Laurier University, Waterloo, ON, Canada

e-mail: spollack@wlu.ca 